Çanakkale Araştırmaları Türk Yıllığı

Yll: 13, Bahar 2015, Sayı: 18, ss. 667-683, 100. Yıl

\title{
Çanakkale Müzik Kültüründe Geleneksel Halk Müziği
}

\begin{abstract}
Alaattin CANBAY*
$\ddot{O} z$

Çanakkale, tarihi ve doğal güzelliklerin yanında özellikle coğrafi konumu nedeniyle kendine özgü ve oldukça renkli bir yapıdaki müzik, oyun ve eğlence kültürüne sahiptir. Çanakkale ilinin coğrafi konumu, müziğini ve geleneksel oyunlarını da etkilemiştir. Köklü tarihi ve kültürel zenginlikleriyle ilin müzik kültürü, Batı Anadolu ve Trakya-Rumeli ezgilerinin adeta bir kaynaşma yeri gibidir. Bu özellik türkülerde ve oyun müziklerinde de kendini açıkça gösterir. Tarihsel süreç içinde birçok kültürün kendine ait izlerini biraktığı bir yerleşim alanı olarak bilinen kentin, müzik, oyun, dans, halk edebiyatı ürünleri, gelenek-görenek ve sosyal yaşam içindeki bütün unsurlarl, zengin bir kültürel çeşitlilik içinde gelişmiştir. Birçok kültürün kesişme ve kaynaşma yeri niteliğinde olan ilin sosyal ve kültürel tüm değerleri gibi geleneksel müzik kültürü ve halk ezgileri de bu sürecin etkisindedir. Çanakkale halk müziği kültürü, coğrafi ve kültürel koşullar göz önünde bulundurularak iki bölge içinde değerlendirilebilir. Il sınırları içerisinde kalan Gelibolu ve Biga yarımadasındaki halk müziği kültürü içinde birbirinden farklı yapılar görmek mümkündür. Genel olarak Balkanlar ve Trakya müzik kültürünün etkisinde kalan Gelibolu yarımadasında başta "karşılama" olmak üzere "hora-horo" gibi oyunlu müziklere ve Trakya bölgesinin müzik geleneğini yansıtan türküler yer alır. Biga yarımadasında ise başta zeybek olmak üzere, güvende, bengi, alay havası ve karşılama türlerini sıkça görmek mümkündür. Ayrıca Türkmen, Çerkez, Boşnak, Pomak vb. topluluklar kendilerine özgü müzik unsurları ile geleneksel kültür içinde önemli bir yer almakta, ilin genelinde müzikal etkinliklerin vazgeçilmez unsurları olarak görülebilecek Roman müzisyenler de kentin müzik ve kültür yaşamına katkı sağlamaktadırlar.
\end{abstract}

Anahtar Kelimeler: Çanakkale Halk Müziği, Çanakkale Halk Kültürü, Geleneksel Müzik.

Doç.Dr., Çanakkale Onsekiz Mart Üniversitesi, Eğitim Fakültesi, Güzel Sanatlar Eğitimi Bölümü, Müzik Eğitimi Anabilim Dalı Çanakkale, acanbay@gmail.com 


\title{
Traditional Folk Music in The Music Culture of Çanakkale
}

\begin{abstract}
In additon to its historical and natural beauty, Canakkale, because of its geographical position, has ideosyncratic and incredibly stirring folk dance, entertainment and music culture. The geographical position of Çanakkale has also affected music and traditional folk dance. By means of its deep-rooted history and cultural wealth, the music culture of the city is like a place where the West Anatolia's and Thracian's melodies meet.This feature manifests itself clearly in ballads and belly dance music. All factors in music, folk dance, dance, production of folk literature, customs and social life of the city, known as the settlement where many culture left their own marks in the historical process, have progressed in rich cultural diversity. Like all social and cultural values of the city which has the characteristics of being intersection of many cultures, traditional music culture and folk melody are under the thumb of this process, as well.

By taking into consideration of its geographical position and cultural position, the folk music culture of Çanakkale can be estimated into two aeras.It is possible to observe different structures in the folk music culture in Gallipoli and Biga Peninsula taking part within the boundaries of Çanakkale. In Gallipoli Peninsula that has been mostly affected by the music cuture of Balkan States and Thracian, folk dance music like especially "karşllama", "hora-horo" and folk song that reflect the music culture of Thracian appear. In Biga Peninsula, it is possible to see especially "zeybek", "güvende", "bengi", "alay havası" and the kinds of "karşılama". Also groups like Turkman, Cherkess, Bosnian and Pomak, with their own musical factors, take an important place in the traditional culture. Gypsy Musicians that can be seen as an indispensable foctor of musical activities in the city also contribute to the city's musical and cultural life.
\end{abstract}

Keywords: Çanakkale folk music, Çanakkale folk culture, Traditional music.

\section{Giriş}

Çanakkale, sahip olduğu tarihî değerlerin yanında kültürel özellikleri ve eşsiz doğa güzellikleri olan aynı zamanda oldukça renkli bir yapıdaki müzik ve oyun kültürüne sahip bir kenttir. Dünya tarihinin en önemli olaylarından biri olan Çanakkale Savaşları́nın geçtiği bu topraklar, insanlık tarihindeki en eski medeniyetlerden biri olan "Troya” uygarlığına ev sahipliği yapmış; nice önemli tarihî ve kültürel hazineye sahiptir. ${ }^{1}$ Kuruluşu Antik Çağ’a kadar uzanan Çanakkale, doğu ve batı kültürünü kendi değerleriyle birleştirerek yöre kültürünün yeniden şekillenmesine ve gelişmesine

1 N.Bora Aydoğan, Çanakkale, TC. Çanakkale Valiliği Tanıtıcı Yayınlar Serisi, Çanakkale 1996, s. 7. 
katkı sağlayan bir kent niteliğindedir. Herkesin geldiği yerden bir şeyler getirerek bu topraklar üzerinde kaynaştırdığı il, ülkenin adeta renkli bir çiçek demeti olma özelliğindedir. ${ }^{2}$ Çeşitli zamanlarda zorunlu şartlar sonucu yaşanan göçlerin Çanakkale kültür ve müzik yaşamına getirdiği çeşitlilik bakımından etkisi, ilin halk kültürü adına önemlidir. Özellikle "93 Harbi” olarak bilinen 1877-78 Osmanlı-Rus Savaşı, ardından 1897 Türk-Yunan ve 1912 Balkan savaşları olmak üzere, süreç içerisinde yaşanan göçlerle Çanakkale'nin nüfusu ve demografik yapısı da değișime uğramıș, birçok yeni köy ve yerleşim biriminin kurulması ile birlikte sosyal, kültürel, ekonomik hareketlilik de hızlanmıștır.

Çanakkale ve çevresine Cumhuriyet döneminde ise 1952-68, 1979-88 ve 19902006 yılları dışında sürekli dışarıdan göçler olmuştur. Tarihsel süreç dikkate alındığında bu bölgenin sürekli göçlere açık bir yer olduğu görülür. ${ }^{3}$ Kurulan yeni yerleşim birimleri ve köylerinde yaşayan insanlar, göç ettikleri yerlerden getirdikleri gelenek, görenek ve alışkanlıklarını doğal olarak sürdürmüş, aynı zamanda yerleşik halkı etkilemiş ve onlardan etkilenmişlerdir. Toprak mülkiyetindeki dağılım ve bireysel yaşam kültürü ezgisel karakteri etkileyerek bölgede sosyolojik olarak farklı bir müzik kültürünün oluşmasına neden olmuştur. Örneğin Doğu ve Güneydoğu Anadolu gibi bölgelerde sıkça rastlanan büyük toprak sahipleri ile orta ve küçük üretim potansiyeli olan gelir grubuna sahip çiftçi-üretici ayrışması veya kısaca "ağa-maraba" ilişkisi türündeki anlatımların burada olmadığı görülebilir. Kendi toprağını, kendi üretim araçları ve çalışma koşullarına göre işleyen insanlar, beraberinde kendilerine göre bir yaşam pratiği ve kültürünü de oluştururlar. Köylü, ağanın toprağını işlemek yerine komşuları ile birlikte kendi toprağını işler; sonra da imece yapar. Makineleşmenin günümüzdeki gibi olmadığı o dönemlerde tarımsal bir işbölümü sonucunda ağır iş gücü gerektiren uğraşların tarlada erkekler tarafından birlikte gerçekleștirilmesi, kadınların ise evde toplanarak başkaca görevleri yerine getirmesi, bu toplulukların ortak beklenti ve kaygılar etrafında toplanarak yaşamlarını kolaylaştırmalarını sağlar. Tarlada biçilen ekin, evde ayıklanan mısır ve ipe dizilen tütünle birlikte maniler, atışmalar, türküler ve oyunlar da oluşur, gelişir ve renklenir, böylece insanlar ve kültürler kaynaşır. Herkesin toprağı, herkesin emeğiyle herkesin ürününe dönüşür. Bereketli topraklar ise mutlu türküler söyletir. Ağanın lütfuna gerek olmadığı gibi gurbet acısına da gerek yoktur. Görüp alamamanın, sevdiğine kavuşamamanın acısı kalmıştır geriye. Bu yapıda gelişen kültür ortamı Çanakkale halk ezgileri ve türkülerinde açıkça görülebilir. ${ }^{4}$

2 Alaattin Canbay ve Ö.Can Satır, Çanakkale Halk Ezgileri, Çanakkale Onsekiz Mart Üniversitesi Yayınları, Çanakkale 2014, s.14-15

3 Mithat Atabay, “Cumhuriyet Döneminde Çanakkale’ye Göçler”, Çanakkale Tarihi, C.VI, Değişim Yay. İstanbul 2008, s. 3315-3332.

4 A.Canbay, age, s.14 
Birçok kültürün kesişme ve kaynaşma yeri niteliğinde olan ilin sosyal ve kültürel tüm değerleri gibi halk ezgileri de bu sürecin etkisiyle gelişmiştir. Tarihî süreç içerisinde çeşitli nedenlerle bölgeye gelen topluluklar kendi kültürlerini de beraberinde getirerek çok kültürlü-birleşik ve kaynaşık bir kültürel yapıyı oluşturmuşlardır. Bunda kuşkusuz ilin iklim koşulları ve verimli toprak yapısı önemli bir etkendir. Bu kültürel gelişim süreci yüzyıllar boyu aralıklarla devam ederek renkli bir kültür mozaiğini ortaya çıkarmıştır. ${ }^{5}$

Kültür yaşamına oldukça güçlü bir biçimde etki eden diğer unsurlardan biri de hiç kuşkusuz 20. yüzyılın başlarından itibaren bütün Anadolu'yu etkisi altına alan savaşlar ve getirdiği acıların yurdun her yerinde olduğu gibi Çanakkale'de de derin izler bırakmasıdır. Her ulusun tarihine bakıldığında, yaptıkları savaşların edebî eserlerinde yansımaları görülebilir. Bu durum Türk edebiyatı için de geçerlidir. Konularının bir bölümünü kahramanlık destanları ve efsanelerinin oluşturduğu türkülerin en duygulu örnekleri bu zamanlarda verilmiştir. Cepheden cepheye gözünü kırpmadan koşan Anadolu evlatları, anaları, bacıları ve sevdaları türkülerine konu olmuş, bu türküler bazen Yemen, bazen de Çanakkale'nin yolunu tutmuştur. Ulusumuzun tarihinde yaşanan ve Dünya tarihindeki en büyük savaşlardan biri olan Çanakkale Savaşları da halkın dilinde müziğe yansımasını böyle bulur. Âşık, şair, besteci ve ozanların, yaşamı böylesine derinden etkileyen bu trajediye duyarsız kalmaları düşünülemez.

\section{Çanakkale Halk Kültüründe Müzik}

Çanakkale ilinin coğrafi konumu, müziğini ve geleneksel oyunlarını da etkilemiştir. Köklü tarihi ve kültürel zenginlikleriyle ilin müzik kültürü, Batı Anadolu ve Trakya-Rumeli ezgilerinin adeta bir kaynaşma yeri gibidir. Bu özellik türkülerde ve oyun müziklerinde de kendini açıkça gösterir. Kuzey Ege, Trakya ve Güney Marmara kültürel özelliklerinin bir kaynaşma noktası olarak değerlendirilebilecek olan Çanakkale ve yakın çevresi, yöresel oyunları ve müzik kültürü bakımından Karşılama ve Hora bölgesi olarak bilinir. Hora, etimolojik olarak dizi, sıralanış, halka kurma, çergeleniş anlamları ile kullanılan bir sözcüktür. Trakya bölgesinde genellikle 10-15 kişilik gruplar halinde el-ele veya kol-kola tutuşarak yürütülen bir halk oyunu türüdür. Hora, erkekler ve kadınlar tarafından ayrı ayrı oynanan bir oyundur. Her ne kadar Trakya bölgesi ile özdeşleşmiş bir oyun gibi görülse de Gazimihal'e göre Anadolu'nun çeşitli yörelerinde farklı oyun figürleri ve kullanılan çalgılarla oynanan bir türdür. ${ }^{6}$ İstanbul'un Anadolu yakasından başlayıp, İzmit, Sakarya; aşağıya doğru Yalova, Bursa, Balıkesir ve nihayet Çanakkale, oyun ve müzik kültürü bakımından birbirlerinden

5 http://www.canakkale.gov.tr/134/canakkalenin-tarihi-2 (21.05.2014)., http://www.canakkale.bel.tr/ (21.05.2014).

6 M.Ragıp Gazimihal, age. 
kısmi farklılıklar gösterseler de ${ }^{7}$, ayrıntılı bir inceleme yapılacak olursa Çanakkale'nin sosyo-kültürel yapısı ve bulunduğu coğrafi konum nedeniyle müzik kültürel anlamda bir kesişim bölgesi olduğu açıkça görülebilir.

Çanakkale'de geleneksel halk müziğine yönelik ilk resmî folklor derlemesi 1947 yılında yapılmıștır. Ankara Devlet Konservatuarı arşivi için Muzaffer Sarısözen, Halil Bedii Yönetken ve teknisyen Rıza Yetişken'den oluşan ekip Çanakkale'de 70 kadar türkü ve ezgiyi plağa kaydetmiştir. ${ }^{8}$ Buradaki verilere göre, derleme ekibi 28.07.1947 ve 02.08.1947 tarihleri arasında merkez ilçe başta olmak üzere, Yenice, Ezine, Bayramiç ve Biga ilçelerinde birçok zeybek, karşılama ve türküyü kayıt altına almıştır. Ahmet Yamacı, Nida Tüfekçi, Serbülent Yasun, Mehmet Özbek, Erkan Sürmen ve Saniye Can’ın Çanakkale geleneksel halk müziği kültürüne değerli çalışmaları ile katkıda bulunan TRT Türk Halk Müziği derlemeci ve sanatçılarıdır. Çanakkale il kültür müdürlüğü bünyesinde görev yapan folklor araştırmacıları Ömer Gözükızıl ve Mümtaz Firat, halkbilimsel ürünlerin araştırılması, derlenmesi ve arşivlenmesi adına Çanakkale halk kültürüne anlamlı katkıları olan diğer önemli araştırmacılardır. Doç. Dr. Alaattin Canbay'ın yürütücülüğünde, 2010 yllında Çanakkale Onsekiz Mart Üniversitesi bilimsel araştırma projeleri koordinasyon birimi tarafından desteklenen ve 2014 yllında tamamlanan proje ile geniş kapsamlı bir arşiv, derleme ve yayın çalışması gerçekleştirilerek, derlenen halk ezgileri kayıt edilerek tasniflenmiş, notaya alınmış ve Çanakkale Halk ezgileri başlı̆̆ı altında bir kitapta toplanmıştır. Alaattin Canbay ve Ö. Can Satır tarafından hazırlanan "Çanakkale Halk Ezgileri" kitabı Çanakkale halk müziği alanındaki en kapsamlı çalışmalardan biri olarak gösterilebilir.

\section{Çanakkale Halk Ezgileri}

Halk ezgileri, toplumların kendilerini sesli ve ezgisel olarak ifade ettikleri ortak bir anlatım biçimi olan kültürel unsurlardır. İnsan yaşamı içindeki bütün doğal ve toplumsal olaylar sesle birlikte ezgisel bir yapıya dönüştürülerek geleneğin en önemli taşıyıcı unsuru haline gelir ve halk ezgilerini oluştururlar. İç sesini duygusal bir ifadeyle anlamlandıran insan, iş türkülerine kattığı coşku, oyun ezgilerinde neșe, ağıtlarına hüzün ve ninnilerine sedasıyla, müziği yaşamının vazgeçilmez bir parçası yapar. Halk ezgileri bu anlamıyla kültürel kimliğin oluşması ve devam etmesi adına yaşamsal öneme sahiptir. Halk ezgileri, toplumların yaşam biçimlerine, yaşadıkları olaylara, olayları yorumlama biçimlerine göre yerel-toplumsal veya uluslararası olmak üzere çeşitli farklılıklar gösterebilirler. Ezgilerin ritim (usul) yapıları, ses genişliği ve ezgisel yapıları veya konuları yerel ve ezgisel olarak farklı özellikler taşıyabilir. Genel olarak

7 Melih Duygulu, Türkiye'de Çingene Müziği, Pan Yay., İstanbul 2006, s.176.

8 Armağan Elçi, Muzaffer Sarısözen:Hayatı, Eserleri ve Çalışmalar,Kültür Bakanlığı Yay., Ankara, 1997. 
"tavır” olarak adlandırılan bu anlatım şekli aynı zamanda Türk halk müziğinin çeşitliliği ve zenginliğinin de bir göstergesidir. Sosyal bir temele, yüklü bir duyguya, kalıcı bir müziğe dayanan halk ezgileri, asker ocağında, düğün dernek ve kır eğlencelerinde, okullarda; halk sanatçıları, öğretmenler, askerler, köçekler ve çalgıcılar aracılığıyla daha geniş çevrelere yayılırlar. Geniş iskân hadiseleri bir yörenin kültürünü başka bir yöreye taşıdığından halk ezgileri ve bu ezgisel yapı içinde önemli unsurlardan biri olan türkülerin yayılmasına da katkıda bulunurlar. Çanakkale halk ezgileri buna güzel bir örnektir. Halk ezgileri, aynı zamanda toplumların kendilerini ifade ettikleri ortak bir anlatım biçimi olan kültürel unsurlardır. Üretim-tüketim ilişkilerinin oluşturduğu yaşam pratiği, coğrafi koşullara göre değiştiğinde halkın dilindeki ezginin yapısı da o oranda değişir. Aynı durum yaşanan sosyal olaylar sonucunda oluşturulan ezgiler için de geçerlidir. Aşklar, acılar, ayrılıklar, gurbet, sıla, özlem, savaşlar, kahramanlıklar, düğünler, eğlenceler; insana ve yaşama ait tüm değerler halk ezgilerinde dile gelir. Birçok kültürün iç içe kaynaştığı, bütünleştiği, gerçek olayların destanlaştığ 1 Çanakkale'de halk ezgilerinin de aynı biçimde geliştiği görülür. Birlikte söylenen türküler, maniler, atışmalar, dil ahenginin ve kültür dağarcığının zenginliğini alabildiğince sergiler. ${ }^{9}$

\section{Çanakkale Geleneksel Halk Müziğinde Türler}

Çanakkale halk müziği kültürü, coğrafi ve kültürel koşullar göz önünde bulundurularak iki bölge içinde değerlendirilebilir. İl sınırları içerisinde kalan Gelibolu ve Biga yarımadasındaki halk müziği kültüründe birbirinden farklı yapılar görmek mümkündür. Bu durum Çanakkale'nin zengin bir müzik kültürüne sahip olduğunun en önemli göstergesidir. Avrupa yakasında kalan Gelibolu Yarımadası'nın geleneksel müzik kültürü, coğrafi konumunun da etkileri ile Balkanlar ve Trakya müzik kültürü ile etkileşim içindedir. Burada başta karşılama olmak üzere hora-horo gibi oyunlu müziklere ve Trakya bölgesinin müzik geleneğini yansıtan türkülere oldukça sık rastlanır. Bunun yanında özellikle Gelibolu ilçesinde yaşayan Roman topluluklarının kendilerine özgü müzik gelenekleri Çanakkale halk müziğinin önemli unsurları arasında gösterilebilir. Başta zeybek olmak üzere güvende, bengi, alay havası ve karşılama türlerinin görülebileceği Biga Yarımadası'ndaki halk müziği kültürünün Gelibolu Yarımadası'na oranla daha fazla çeşitlilik gösterdiği söylenebilir. Bengi, Ege bölgesinde özellikle Balıkesir ve Bursa yörelerinde karşılaşılan, zeybek karakterini andıran vokal-enstrumantal tarzdaki oyunlu ezgilerdir. ${ }^{10}$ Güvende, 1, 2, 3 veya 4 kişinin "sekme" yi zil takarak oynadıkları, Bursa ve Balıkesir oyunları arasında yer alan bir oyundur. $^{11}$

$9 \quad$ A.Canbay, age, s.12

10 Süleyman Şenel, Türk Halk Musîkisi Bilgileri, (Basılmamış Ders Notları), İTÜ TMDK, İstanbul 1998,

11 M.R. Gazimihal, age. 
Bölgenin müzik kültürüne esas teşkil eden bu türlerin yanında, yoğun olarak Bayramiç, Ezine ve merkez ilçe çevresinde yaşayan Türkmen Alevilerin Cem'lerde icra ettikleri Semahlar ile Çan, Biga ve Gelibolu çevresindeki Pomak, ayrıca Biga'da yerleşik Çerkez toplulukların müzik kültürleri, Çanakkale halk müziğinin çok kültürlü yapısının renkli bir yansıması niteliğindedir. Bu renkli yapı içerisinde, Çanakkale müzik kültürünü zenginleştiren bir diğer etken de müzisyenlerin hareketliliğidir. Düğünlerin ve eğlence yaşamının vazgeçilmez unsurları olan Roman müzisyenler il içinde olduğu kadar, il dışına yaptıkları seyahat ve iş gezileri sırasında kültürel bir hareketlilik oluşturmuşlardır. Yakın bölgelere müzisyenlik amacıyla yapılan seyahatlerin yanında, mevsimsel olarak Ege bölgesinin farklı illerine çalışma amacıyla giden müzisyenler gittikleri yerlere Çanakkale ezgilerini götürürken, farklı bölgelerde öğrendikleri ezgileri Çanakkale'ye taşıyarak burada icra etmeye başlamışlardır. Kaynak kişilerle yapılan görüşmelerden edinilen bilgilere göre; 1950 ve 60'lı yıllarda başta Bayramiç ve Ezine olmak üzere Çanakkale kent merkezi ve ilçelerinde yaşayan müzisyenlerin çalışmak amacıyla Muğla, Aydın ve Ege bölgesinin farklı illerine giderek müzisyenlik yapmaları ve ezgilerin bu yolla çeşitli varyantlar halinde icra edilmesi söz konusu duruma örnek gösterilebilir. Ayrıca bu bölgede yapılan deve güreşlerinin de bu bağlamdaki repertuar etkileşimi için önemli bir unsur olduğu bilinmektedir.

\section{Çanakkale Halk Türküleri}

Halk türküleri veya şarkıları, bireysel ya da ortak yaşamsal etkinlikleri dile getirmek için söylenen sözlü-ezgili halk edebiyatı ürünleridir. Halk şarkılarında, insanların yaşadıkları doğum, ölüm, aşk, ayrılık, doğa gibi konular işlenir. İçerdiği konu, ezgi yapısı ve etki gücü doğrultusunda genel olarak zamanla anonim bir özellik kazanan türküler, Geleneksel Türk Halk Müziği'nin en bilindik formu olup, "12. Yüzyll Farsçasında Türk'e ait, Türk'e mahsus anlamına gelen 'Türk-î’ den gelmiş, Türk sözcüğüne bir aidiyet eki olan (î) vokalinin eklenmesiyle Türkçe telaffuza uydurulmuştur. ${ }^{12}$ Türküler, genellikle gerçek hayatta yaşanan toplumsal olay ve beklentilerin yarattığı duygulanma sonucunda ortaya çıkan halk ürünleridir. "Halkın tüm yaratmaları somut bir gereksinimi karşllamaya yöneliktir. Bu yaratmalarda başta sanatsal (estetik) nitelik olup olmaması önemli olmayıp "kullanışlılık" yeterlidir. ${ }^{13}$ Başlangıçta bir olay, bir duygu coşkunluğu sonucunda halk arasında doğan türküler, zamanla geniş bir alana yayıldığında hem müzik, hem de şiir bakımından değişmeye, düzelmeye ve daha kolektif duygular taşımaya başlarlar. ${ }^{14}$ Bu nedenle halk ezgileri ve türküler bir anlamda geleneğin gerçek taşıyıcısı gibidir. Gezici bir saz aşığının dilinde diyardan

12 Mustafa Hoşsu, Geleneksel Türk Halk Müziği Nazariyatı, Kombassan Yay. İzmir. 1997, s.6.

13 Ümit Kaynar, Türk Halk Kültürü ve Halk Müziği, Ege Yay. İstanbul 1996, s.24.

14 Mehmet Özbek, Folklor ve Türkülerimiz, Ötüken Yay., İstanbul 1981, s. 64-65. 
diyara dolaşan türküler, içlerinde kültürel ve tarihî birçok unsuru taşır. Hece ölçüsü ve ezgi kalıbına sarılmış türküler bu yolla hem akılda daha kolay kalır, hem de çabuk öğrenilerek yaygınlaşabilir. Yazılı ve kayıtlı geleneğin bozulma veya unutulma sorunu türkülerde daha az görülür. Halkın zihninde yer etmiş, gerçek bir öykü veya olayı anlatan türküyü değiştirmek veya yok etmek mümkün olmadığından, türküler; bu anlamda gelenek ve kültürü en özenli biçimde geleceğe aktarma işlevini üstlenirler. Fuad Köprülü’ye göre; Türki, Türk'e özgü tanımlarıyla, “Türklere mahsus bir besteyle söylenen halk şarkıları" olarak da tanımlanırlar. ${ }^{15}$ Halk Türküsü genel bir ifadeyle, "başlangıçta bir kişinin, hafızasında var olan halk işi ezgi ve söz kalıplarından yararlanarak, bazen sözlü, bazen ezgiyi değiştirerek, bazen de yine halk işi olmak kaydıyla, özgün olarak ortaya koyduğu; dilden dile dolaşırken değişikliğe uğrayan, zaman içinde kişisel izlerin silinmesi sonucu ortak özellik taşıyan ezgili ve biçimli sözler" ${ }^{16}$ olarak tanımlanabilir.

Türküler; genellikle, Bağlama, Kemençe, Mey, Klarnet gibi sazlar eşliğinde söylenebildiği gibi çalgı eşliği olmaksızın da "yakılabilir" ve söylenebilir. Yörelere göre farklı halk çalgıları ile icra edilen türküler, çalgı eşliği olmaksızın kolaylıkla çalınan ve söylenen bir ezgisel karaktere sahiptir. Bununla birlikte ülkemizde her yörenin kendine ait türküleri ile özdeşleşmiş çalgıları, türkünün icrasını yayılmasını daha etkin bir hale getirir. Örneğin Karadeniz türküsünde kullanılan kemençe veya Toroslarda çalınan kabak kemane türkülerin icralarındaki heyecanı dile getirir. Kültürlerin kaynaşması ve iç içe geçmesi ile birlikte yörelerin geleneksel kültürüne ait olmayan çalgılarla da icra edilebilen türküler, çalgı kullanımı bakımından halk kültürünün renkli bir formunu oluşturur. Çeşitli nazım şekilleri ve ezgiler kullanılarak oluşturulan türküler, konu, ezgi ve şekil özelliklerine göre pek çok anonim manzumeyi içinde barındırırken, ezgisel yapı bakımından Kırık Havalar ve Uzun Havalar olmak üzere iki ana bölümde incelenebilir. Türk halk müziğinin beslendiği en önemli iki kaynak, Âşıklar (Halk Ozanları) ve “Türkü Yakıcılar”dır. Türkülerin biçim ve konu bakımından gelişmesine, yakılmasında ve yayılmasında saz şairlerinin, halk ozanlarının, âşıkların ve türkü yakıcıların önemli katkıları bulunmaktadır.

Türkünün ana biçimi dörtlüktür. Dörtlükler çoğu zaman birbirine eklenerek ve "Bağlantı (nakarat, kavuştak)"lar alarak daha uzun birimler halinde söylense de iki veya üç dizeden oluşan türküler de vardır. Türkülerin büyük bir bölümü manilerin yan yana gelmesinden oluşur. Mani dizeleri aralarına, başlarına, sonlarına veya dörtlüklerin ardından bağlantılar alarak türküye dönüşür. Böylece uzun mani kararları, ezgilere bağlanarak türkü halini alır. ${ }^{17}$ İcracının, türkünün bilinen dörtlüklerine ek olarak kendisinin daha önceden öğrendiği veya o anda irticalen söylediği uygun ya-

15 Nihat Taydaş, "Ah Bu Türküler Köy Türküleri”, Folklor/Edebiyat Dergisi, C.11, S.42, 2005, s.103.

16 Mehmet Özbek, Türkülerin Dili, Ötüken Yay. Ankara 2009, s.19.

17 İlhan Başgöz, age, s.137-138. 
pıdaki sözleri, ezgiye uygun ve türkünün devamı olarak söylemesi de sıkça görülen bir durumdur. Karşılıklı söylenen-atılan manilerin ezgi yapıları ile bütünleştirilerek türkü olarak söylenmesi, anonim bir halk yaratısı özelliği gösteren türküler için olağan bir süreç olduğu söylenebilir. Bu yapıya uygun "Kayadere Çamları"18 adlı türkü örnek olarak gösterilebilir; ${ }^{19}$

\section{KAYADERE CAMLARI}

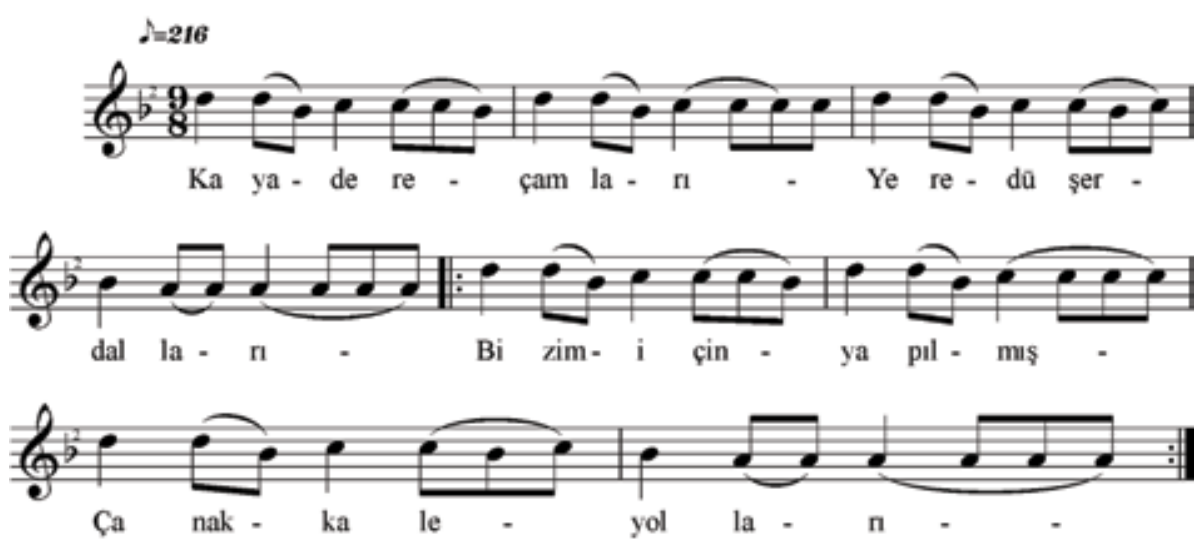

Kayadere çamları

Yere düşer dalları

Bizim için yapılmış

Çanakkale yolları

Kayadere köyümüz

Zemzem akar suyumuz

Sevip sevip ayrlmak

Yoktur öyle huyumuz

Çanakkale türkülerindeki belirgin özelliklerin başında, ülkemizin diğer bölgelerinde olduğu gibi ezgili mâni söyleyiş biçimi gelir. Anonim halk edebiyatının en yaygın nazım şekli olan "mâni”, halk şiiri metinlerinin önemli bir kısmını ve diğer manzum ürünlerin çoğunu oluşturması bakımından önemlidir.

18 Yöre; Kayadere Köyü, Kaynak Kişi; Mehmet Küçük-Mustafa Kısa, Derleyen ve notaya alan; Yücel Kökdere, Derleme Tarihi; 17.01.2001,

19 A.Canbay, age., s. 135 
Halk edebiyatımızın en yaygın türlerinden biri olan mâninin özelliği, değişmez bir kural olmamakla birlikte bağımsız dörtlüklerden oluşması ve doğaçlama yaratılmasıdır. ${ }^{20}$ Çanakkale türkülerinin önemli bir kısmı, mâniler arasına serpiştirilen nakaratlar yardımıyla oluşmaktadır. Bilinen bir ezgiye (örneğin Evreșe Yolları) türkü icracıların mâni eklemeleri ve böylece türkünün sözlerini uzatmaları veya değiştirmeleri de mümkündür. Türküler; yaşanan olayların yanında aynı zamanda duygu ve düşünceleri de dile getirir. Genellikle ezgili maniler olarak nitelendirilebilecek Çanakkale türkülerinin konularına göre aşk-sevda, kız-oğlan-aile büyükleri arasındaki ilişkiler etrafında yoğunlaştığı görülür. Türkülerde, gurbet, kahramanlık, merkezi otoriteye başkaldırı gibi konulara pek rastlanmadığı gibi ağıt niteliği taşıyan halk ezgileri veya türküler de nadiren görülür.

\section{Zeybekler}

Çanakkale halk müziğini oluşturan en önemli türlerden biri zeybeklerdir. Zeybek, belirli bir oyun figürüne bağlı, çalgısal veya sözel biçimlerde icra edilen geleneksel bir müzik türüdür. Adını 17. Yüzyıl sonlarından 20. Yüzyılın ilk çeyreğine kadar olan dönemde Batı Anadolu'da yaşamış eşkıya gruplarından almaktadır. ${ }^{21}$ Gazimihal'e göre zeybek sözcüğü "salbak" ya da bunun diğer bir söylenişi olan "saybak (cesur)" sözcüklerinden türemiștir. ${ }^{22}$ Saldırmak, hareket etmek ve bir yere gitmek anlamına gelir. ${ }^{23}$ Geleneksel yapılarına bakıldığında zeybeklerden oluşan isyancı topluluğun içinde bulunan bireylere "zeybek", çetenin başında bulunan öncülüğünü ve sorumluluğunu üstlenen zeybeğe ise "efe" denildiği görülür. ${ }^{24}$ Zeybek oyunları, açık havada, davul-zurna veya yöresine göre klarnet, bağlama, kadınlarda ise def, darbuka, leğen gibi "dımıdan" sazlarla eşlik edilerek oynanır. ${ }^{25}$ Anadolu'nun batı yarısının hemen her yerinde, doğuya gittikçe azalan bir şekilde çeșitli varyantlarıyla zeybek oyunları büyük bir yaygınlıkta oynanmaktadır. Batı Anadolu'da halk tarafından çalınan ve oynanan oyunlara da "Zeybek Havası" veya "Zeybek Oyunları" denilmektedir. Zeybeklere has oyun anlamında zeybek oyunu, oyun kelimesi katılmaksızın da zeybek, bu yörenin kendi oyun çeşitlerinin toplu adı olduğu söylenebilir. ${ }^{26}$

Zeybek müziği, ezgisel ve ritmik yapıları ile diğer türlerden ayrılır. Bu ritmik yapılar, davulun tokmağı, bağlamanın mızrabı ile doğal ve duygusal olarak, belirli za-

20 İlhan Başgöz, age. s.103.

21 Hamit Çine, Zeybek Oyunlarımız, Mey Yay., İzmir 1994, s.13.

22 M.Ragıp Gazimihal, Musiki Sözlüğ̈̈, MEB Yay., İstanbul 1961, s.274-275.

23 TDK, Türkiye'de Halk Ağzından Derleme Sözlüğ̈̈, C 12, TDK. Yay., Ankara 1982, s.4828

24. A.Haydar Avcı, Zeybeklik ve Zeybekler, Bir Başkaldırı Geleneğinin Toplumsal ve Kültürel Boyutları, Verlag Anadolu Yay., Hückelhoven 2001, s.18.

25 Hamit Çine, age, s.23

26 M.Öcal Özbilgin, Zeybeklik Kurumu ve Zeybek Oyunları, (Yayımlanmamış Doktora Tezi) EÜ. Sos.Bil. Ens. Folklor Bilim Dalı, İzmir 2005, s.69. 
man birimleriyle ölçüye vurulmuş ve oyunların hareketleri bu tempolarla aktarılarak devam etmiştir. Yaşanan her olayın konusu, oyuncuların kişisel özellikleri ve oyunla gösterdikleri uyum zeybek oyunu ve müziğini etkileyen unsurlardır. Müzikal olarak türü belirleyen en önemli öğe zeybeğin dokuz zamanlı usul yapısıdır. Bunun yanında kendine özgü tavır ve üslup barındıran köklü bir icra geleneğine sahiptir.

Çanakkale zeybekleri ve zeybek müzikleri, yöre müzik kültürünün diğer örneklerinde görülebileceği gibi çevresel unsurlarla etkileşim içindedir. Zeybeklerde müzikal yapıyı oluşturan ritim-ezgi ve icra biçimi bu etkileşim sonucunda kendi karakterini ortaya koyar. Kuzey Ege'nin Çanakkale'den başlayarak İzmir ve Muğla'ya doğru giden coğrafi alan içinde birçok yönü ile ortak ve birbirine benzeşik bir müzik kültüründen söz edilebilir. Örneğin, bu bölgede icra edilen bir zeybeğin sahip olduğu yapısal özelliklere, İzmir Bergama'dan başlamak üzere, Edremit ve Balıkesir'in Çanakkale'ye yakın yerleşimlerinde de rastlanabilir. Bu anlamda Çanakkale zeybekleri ile bölgenin diğer zeybekleri arasında belirgin farklılık bulunmadığından söz etmek mümkündür. Kültürel anlamda yakın özellikler taşıyan bölgenin diğer zeybekleri, Çanakkale'de icra edilebilir ve oynanabilir.

Kuzey Ege zeybek kültürünün önemli bir parçası olan Çanakkale il sınırları içinde yaygınlık kazanan belirli zeybekler şu şekilde sıralanabilir:

- Ada Zeybeği

- Alay Havası

- Bağözü Zeybeği

- Çan Sekmesi (Süzme)

- Çanakkale Zeybeği

- Çiftleme Zeybeği (Karanfilin Moruna)

- Deniz Göründü Zeybeği

- Edremit Zeybeği

- Goca Hava Zeybeği (Düz hava)

- Harmandalı (Madran Zeybeği)

- Kaba Güvende (Kaba Güvengi)

- Karanlıkdere (Çaparlı Zeybeği)

- Karyolamın Demiri (Yandım Ayșem)

- Kusköy Zeybeği

- Ninnalar (Nevruz) 
- Sürmeli

- Tabancalı zeybeği

Başta Çanakkale'nin Biga ilçesi olmak üzere Ezine ve Bayramiç’te yaygın olarak icra edilen "Karanlıkdere (Çaparlı) Zeybeği" nin notalarına aşağıda yer verilmektedir. Derlemesini Çoşkun Bağcıoğlu ve Ersin Mirze'nin yaptığı Zeybek, Yalçın Kırıkkulak'tan derlenmiş ve Coşkun Bağcıoğlu tarafından notaya alınmıştır. ${ }^{27}$

\section{KARANLIKDERE ZEYBEĞİ}
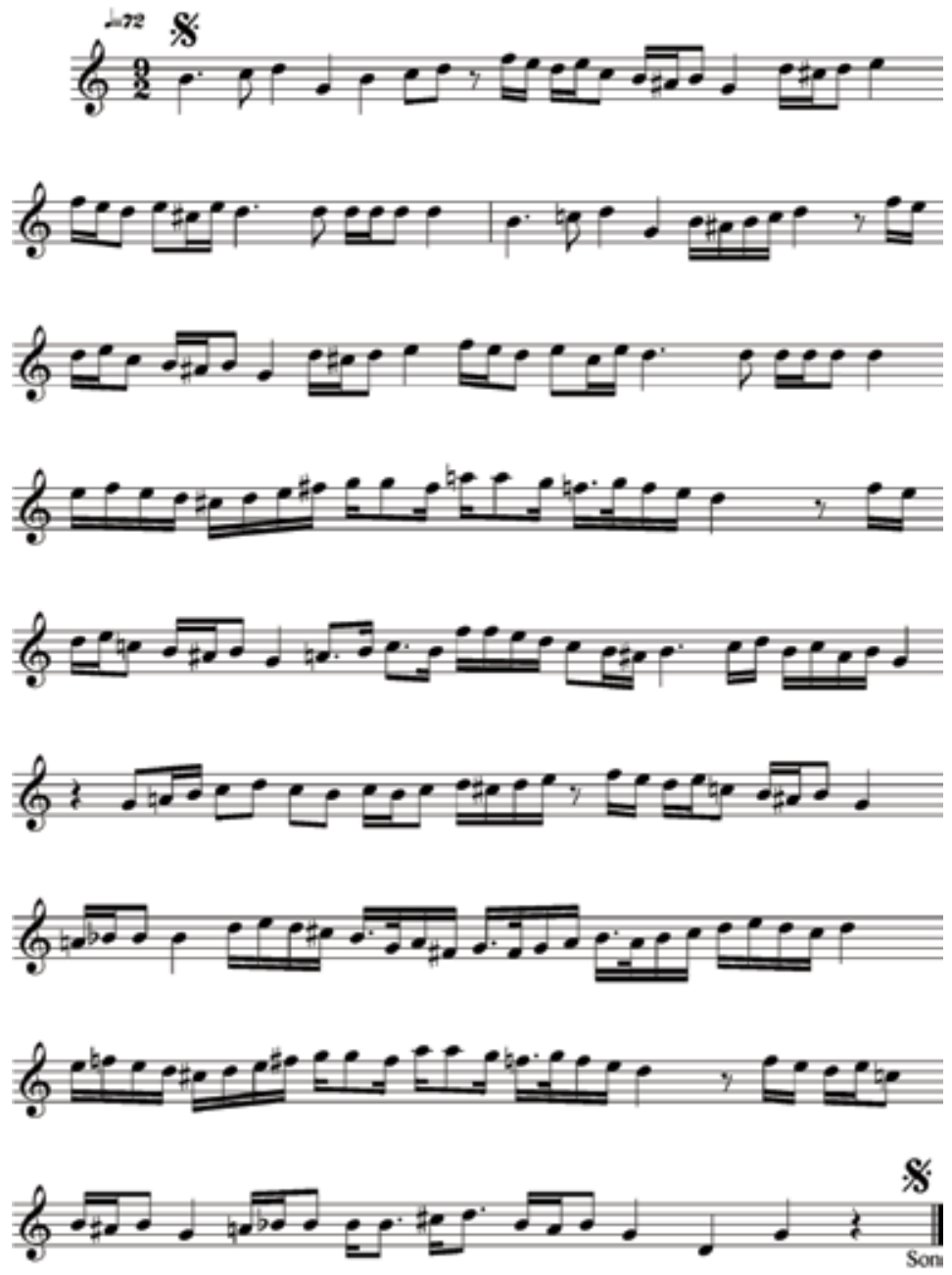

27 A.Canbay, age., s. 206 


\section{Karşılamalar}

Karşılama türündeki ezgiler, Çanakkale'nin müzik ve oyun kültüründe ayrı bir yer tutar. Trakya bölgesinde yaygın olarak icra edilen bu tür, etki sahası bakımından Gelibolu yarımadasını da içine alan bu bölgede de varlık göstermektedir. Aynı zamanda hareketli-yürük bir ezgisel seyir özelliği gösteren karşlamalar her ne kadar farklı coğrafyalarda değişik müzikal dinamiklere sahip olsalar da, bu türü belirleyen en önemli öğe dokuz zamanlı usul yapısıdır. Karşılamalara Trakya dışında Anadolu'nun farklı bölgelerinde de rastlanabilir. Gazimihal, Türk Halk Oyunları kataloğunda Doğu Anadolu oymaklarında kadın ve erkeklerin karşılıklı yürüttükleri oyunlardan söz etmektedir. Çanakkale’ye ait karşılamalar, Biga ve Gelibolu Yarımadasında görülmektedir. Bu oyun kadınlar tarafından eşli olarak iki, dört veya altı kişiyle oynanabilmektedir. Yaygın olarak icra edilen karşılamalardan bazıları şunlardır; "Versinler" (Gelibolu), “Annem Entari Almış" (Gelibolu), "Sira Sira Siniler” (Gelibolu), "Evreşe Yolları Dar” (Gelibolu), "Çemberimde Gül Oya” (Gelibolu), "Bayramiç’in Dağları” (Bayramiç), "Lapseki Çeşmesi” (Lapseki), "Siirtme” (Çan).

Çanakkale Lapseki'den Yaşar Şen tarafından İsmail Güney ve Nazife Ergin kaynak kişilerinden derlenen ve Altan Demirel tarafından notaya alınan "Ayna Çaktım Yüzüne (Versinler)” adlı Karşılama'nın sözleri ve notaları aşağıda yer almaktadır;

Ayna çaktım yüzüne

Şavkı vurdu gözüme

Sana söylüyorum yar

Kulak versen sözüme

Versinler, versinler

Sevenleri sevdiğine versinler

Yar mendilin oyaladim

Baş harfini koyamadım

Eller ald y yarini

Ben yarime varamadim

Versinler, versinler

Sevenleri sevdiğine versinler

Karşımızda Gelibolu

Gelibolu'da yatır dolu

Beni sana verecekler

Yar dualarim kabul oldu 


\section{AYNA ÇAKTIM YÜZÜNE \\ (Versinler)}
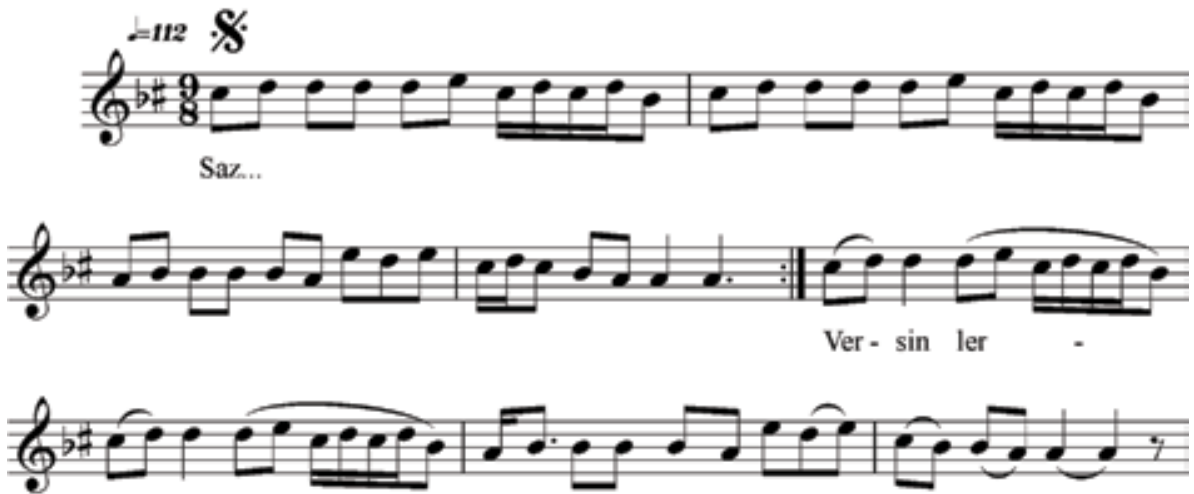

ver- $\sin$ ler - $\quad$ Se ven le ri sev di gi ne - ver - sin - ler -

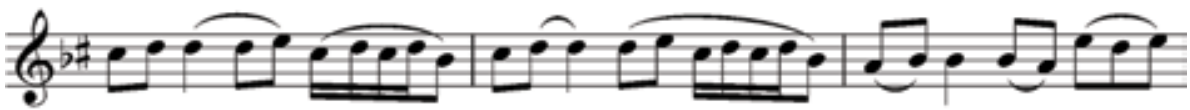

Ay na çak - tum - yũ zū - ne - Şav - kı vur - du -
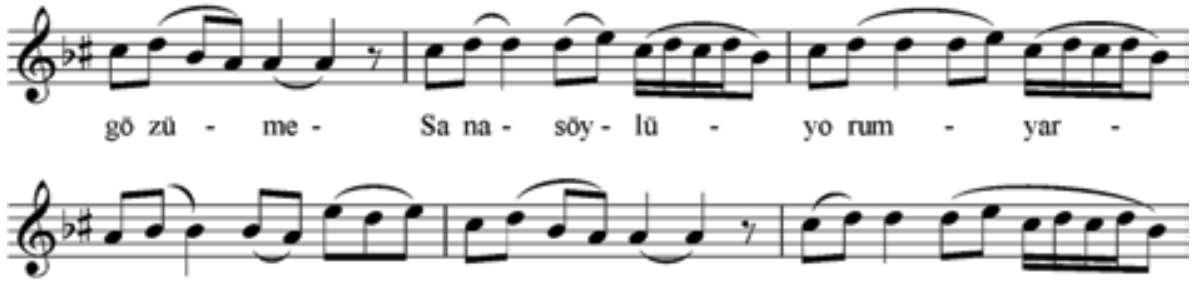

Ku lak - ver - sen - sō zū - me - Ver - sin ler -

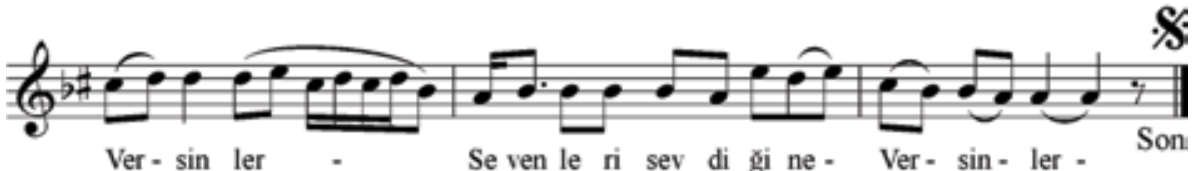

Se ven le ri sev di gi ne - Ver - sin - ler

\section{Çanakkale Geleneksel Halk Müziğinde Çalgılar}

Çanakkale'de yaygın olarak görülen çalgıların başında Klarnet-Davul ikilisi gelmektedir. Dügün ve eğlencelerin yanında yöresel müziğin icrasında da kullanılan klarnetin özellikle 20. Yüzyılın başlarında zurnanın yerini aldığı bilinmektedir. Genellikle bölgede yaşayan Romanlar tarafından icra edilen, Davul-Zurna veya sonrasında Davul-Klarnet, Çanakkale müzik kültürünün genel karakteristiğini yansıtan çalgılar olarak bilinmektedir. Klarnetin ayrıca yerli müzik icrasına bandonun da et- 
kisiyle ağılıkla kullanılmaya başlanması, zurnaya göre kapalı yerlerde ve fasıllarda daha çok tercih edilmesi de bunda etkendir. Günümüzde Çanakkale Merkez, Bayramiç, Biga, Ezine, Yenice gibi yerlerde, klarnet çalanların büyük bölümünün babalarının aynı zamanda zurna çalıcısı da olduğu bilinmektedir. Örneğin Yenice'de 20-25 yıl öncesine kadar düğünlerin zurna ile yapıldığı ve çalıcılarının da büyük ölçüde Roman müzisyenlerden oluştuğu görülür. Zurnadan klarnete geçen Romanların dışında zurna veya klarnet çalıcısına az da olsa rastlanmaktadır. ${ }^{28}$

Bağlama çalma ve Bağlama ile türkü söyleme geleneğinin, Çanakkale'de Türkmenlerin dışında fazlaca yaygın olmadığı bilinmektedir. Yörük ve Türkmenlerin çeşitli etnik gruplarla yeteri kadar iletişim ve kültürel işbirliği içinde olamamaları çalgısal anlamda da bir çeşitliliği engellemiş olabileceği düşünülebilir. Tekke geleneğinin burada yeteri kadar yaygın olmaması, Bağlama ile icra edilen Aşık Edebiyatı ürünlerinin sosyo kültürel nedenlerle yaygınlaşamaması ve uzantısında Aşık Kahvehanesi kültürü olmadığı için Bağlamanın yaygın kullanımına sık rastlanmamaktadır. Türkmen kültüründe "Cem Aşı̆̆ı" olarak tanınan "Sazandar" lar, kendilerine özgü çalıș biçimleriyle Alevi-Türkmen müzik kültürünü sürdürmektedirler.

Çanakkale'de Klarnet-Davul yanında, Kanun, Keman, Ud, Saksafon ve Darbuka, Def gibi ritim çalgıları da ağırlıklı olarak Çanakkale Romanlarının düğün ve eğlencelerde kullandıkları çalgılar arasındadır. Kırsaldaki düğünlerde özellikle kadınların eğlenirken kullandıkları Def, 25-30 cm. çapında, 10-15 cm. eninde kasnağın tek veya her iki tarafına gerilen deriden oluşan bir ritim çalgısıdır. Çanakkale'deki kadınlar arasında zilli ve zilsiz olmak üzere her iki türü de çalınır ve Trakya'da olduğu gibi "dömbelek" veya "dönbek" olarak bilinir. ${ }^{29}$

Özellikle Çerkezlerin kullandığı, düğünlerde ve müzikli eğlencelerde akordeona eşlik eden "Pheçiç" (peçiç) ise, bir ucundan birbirine tutturulmuş 6-7 adet ince tahtanın birbirine vurulmasıyla, el çırpma sesinin elde edildiği bir ritim çalgısıdır. Akordeonun yanında yine Çerkezlerde "Pşine" çalgısı da kullanılmaktadır. Bunun yanında, özellikle Gökçeada'da “dilli damak” adı verilen ve genellikle çalıcısı tarafından yapılan, tiz sesli sipsiye benzer bir çalgı ve çok yaygın olmamakla birlikte kaval da bulunmaktadır.

\section{Sonuç}

Köklü tarihi ve kültürel yapısıyla Çanakkale, zengin bir müzik ve oyun kültürüne sahiptir. İçinde bulunduğu coğrafi konum, Batı Anadolu, Trakya, Rumeli ve Anadolu coğrafyasının müzik kültürel değerlerini birleștirir ve kaynaştırır. Geleneksel halk

28 Ömer Gözükızıl, Kişisel Görüşme Notları, 20.06.2012.

29 Melih Duygulu, age., s. 123-124. 
türküleri ve Zeybekler yanında, Karşılama ve Hora'lar geleneksel halk müziği kültüründe önemli bir yer tutar. Çanakkale halk türküleri, ülkemizdeki diğer örneklerine benzer yapısıyla "ezgili mâni" söylenişi biçimindedir. Çanakkale türkülerinin önemli bir kısmı, mâniler arasına serpiştirilen nakaratlarla oluşmaktadır. Bilinen bir ezgiye türkü icracıların mâni eklemeleri ve böylece türkünün sözlerini uzatmaları veya değiştirmeleri de mümkündür. Genellikle ezgili maniler olarak nitelendirilebilecek Çanakkale türkülerinin konularını ağırlıklı olarak aşk-sevgi-sevdalanma, kız-oğlan, aile ve benzeri sosyal ilişkiler yanında nadiren de diğer sosyal ve toplumsal konuların oluşturduğu görülür.

Çanakkale geleneksel halk müziği kültüründe önemli türlerden biri olan zeybekler ve zeybek müzikleri yöre kültürünün diğer örneklerinde de açıkça görülebileceği gibi çevresel unsurlarla etkileşim içindedir. Kuzey Ege'nin Çanakkale'den başlayarak İzmir ve Muğla'ya doğru giden coğrafi alan içinde birçok yönü ile ortak ve birbirine benzeşik bir müzik kültüründen söz edilebilir. Örneğin, bu bölgede icra edilen bir zeybeğin sahip olduğu yapısal özelliklere, İzmir Bergama'dan başlamak üzere, Edremit ve Balıkesir'in Çanakkale'ye yakın yerleşimlerinde de rastlanabilir. Bu anlamda Çanakkale zeybekleri ile bölgenin diğer zeybekleri arasında belirgin farklılık bulunmadığından söz etmek mümkündür. Kültürel anlamda yakın özellikler taşıyan bölgenin diğer zeybekleri, Çanakkale'de icra edilebilir ve oynanabilir. Karşllama türündeki ezgiler ise, Çanakkale'nin müzik ve oyun kültüründe ayrı bir yer tutar. Trakya bölgesinde yaygın olarak icra edilen bu tür, etki sahası bakımından Gelibolu yarımadasını da içine alan bu bölgede varlık göstermektedir. Hareketli-yürük bir ezgisel seyir özelliği gösteren karşılamalar her ne kadar farklı coğrafyalarda değişik müzikal dinamiklere sahip olsalar da, en önemli öğeleri dokuz zamanlı usul yapılarıdır.

Çanakkale geleneksel halk müziği kültürünün başlıca çalgısı Davul ve Klarnettir. Klarnetin özellikle 20.yüzyılın başlarında zurnanın yerini aldığı bilinmektedir. Kanun, Keman, Ud, Saksafon ve Darbuka, Def gibi ritim çalgıları da ağırlıklı olarak Çanakkale Romanlarının düğün ve eğlencelerde kullandıkları çalgılar arasındadır. Bağlama çalma ve bağlama eşliğinde türkü söyleme geleneği daha çok Türkmenler arasında yaygındır."Cem Aşığı" olarak bilinen "Sazandar" lar, kendilerine özgü çalış biçimleriyle Alevi-Türkmen müzik kültürünü yaşatmaya çalışmaktadırlar. Bunun yanında, Çerkezlerin kullandığı akordeon, pşine ve peçiç yanında, Gökçeada da yapılan "dilli damak" Çanakkale geleneksel halk müziği kültürü içinde görülebilecek çalgılardir. 


\section{KAYNAKÇA}

Atabay, Mithat, "Cumhuriyet Döneminde Çanakkale'ye Göçler, Çanakkale Tarihi, C.VI, Değişim Yay. İstanbul 2008, s. 3315-3332.

Avcı, A.Haydar, Zeybeklik ve Zeybekler, Bir Başkaldırı Geleneğinin Toplumsal ve Kültürel Boyutları, Verlag Anadolu Yay., Hückelhoven 2001.

Aydoğan, N.Bora., Çanakkale, TC. Çanakkale Valiliği Tanıtıcı Yayınlar Serisi, Çanakkale 1996. Başgöz, İlhan, Türkü, Pan Yayıncılık, İstanbul 2008.

Canbay, Alaattin, Satır Ö.Can., Çanakkale Halk Ezgileri, Çanakkale Onsekiz Mart Üniversitesi Yayınları, Çanakkale 2014.

Çine, Hamit, Zeybek Oyunlarımız, Mey Yay., İzmir 1994.

Duygulu Melih, Türkiye'de Çingene Müziği, Pan Yay., İstanbul 2006.

Elçi Armağan, Muzaffer Sarısözen: Hayatı, Eserleri ve Çalışmalar, Kültür Bakanlığı Yay., Ankara, 1997.

Gazimihal, M.Ragıp, Musiki Sözlü̆̆̈̈, MEB Yay., İstanbul 1961.

Gözükızıl, Ömer, Kişisel Görüşme Notları, 20.06.2012

Hoşsu, Mustafa, Geleneksel Türk Halk Müziği Nazariyatı, Kombassan Yay. İzmir 1997.

http://www.canakkale.bel.tr/ (21.05.2014)

http://www.canakkale.gov.tr/134/canakkalenin-tarihi-2 (21.05.2014)

Kaynar, Ümit, Türk Halk Kültürü ve Halk Müziği, Ege Yay. İstanbul 1996.

Özbek, Mehmet, Folklor ve Türkülerimiz, Ötüken Yay., İstanbul 1981.

Özbek, Mehmet, Türkülerin Dili, Ötüken Yay. Ankara 2009.

Özbilgin, M.Öcal, Zeybeklik Kurumu ve Zeybek Oyunları, (Yayımlanmamış Doktora Tezi) EÜ. Sos.Bil.Ens. Folklor Bilim Dalı, İzmir 2005.

Şenel, Süleyman, Türk Halk Musîkisi Bilgileri, (Basılmamış Ders Notları), İTÜ TMDK, İstanbul 1998.

Taydaş, Nihat, “Ah Bu Türküler Köy Türküleri”, Folklor/Edebiyat Dergisi, C.11, S.42, 2005.

TDK, Türkiye'de Halk A ğzından Derleme Sözlüğ̈̈, C 12, TDK. Yay., Ankara 1982. 
